\title{
The antioxidant drug "u-74389g" effect on alanine aminotransferase levels
}

\begin{abstract}
The possible recessing capacity of the antioxidant drug "U-74389g" was studied in a rat model. It included the evaluation of the mean alanine aminotransferase (ALT) levels after induced liver ischemia-reperfusion (IR) injury. The 40 used rats were classified at 2 evaluation endpoints: one of $60 \mathrm{~min}$ for groups $\mathrm{A}$ and $\mathrm{C}$ and one of $120 \mathrm{~min}$ for groups $\mathrm{B}$ and $\mathrm{D}$ after reperfusion. The $\mathrm{U}-74389 \mathrm{~g}$ was administered only in groups $\mathrm{C}$ and $\mathrm{D}$. The U-74389g administration non-significantly suppressed the ALT levels $(p=0.4168)$. The reperfusion time kept non-significantly elevated the ALT levels $(\mathrm{p}=0.1309)$. However, the interaction of U-74389g administration and reperfusion time non-significantly suppressed the ALT levels $(\mathrm{p}=0.4527)$. The U-74389g administration non-significantly restored the ALT levels, getting on declining them from significant level to non-significant one.
\end{abstract}

Keywords: ischemia, u-74389g, alanine Aminotransferase, reperfusion, levels, carbohydrate, mineralocorticoid, glucoactive, steroid, pathologic, lipoperoxidation, lipid membranes, methodology, equipment, prenarcosis, standard deviation
Volume 4 Issue 2 - 2017

\author{
Tsompos C, Panoulis C, Toutouzas K, \\ Triantafyllou A, ografos G, Papalois A \\ 'Department of Obstetrics \& Gynecology, Messolonghi County \\ Hospital, Greece \\ ${ }^{2}$ Department of Obstetrics \& Gynecology, Athens University, \\ Greece \\ ${ }^{3}$ Department of Surgery, Athens University, Greece \\ ${ }^{4}$ Department of Biologic Chemistry, Athens University, Greece \\ ${ }^{5}$ Exprerimental Research Centre ELPEN Pharmaceuticals, \\ Greece
}

Correspondence: Tosompos C, Department of Obstetrics \& Gynecology, Messolonghi County Hospital, Etoloakarnania, Greece, Tel 3.06947E+ I I, Fax 3.02107E+ I I,

Email tsomposconstantions@gmail.com

Received: January 01, 2017| Published: February 09, 2017
Abbreviations: ALT, alanine aminotransferase; IR, ischemiareperfusion; IV, intravenous; SD, standard deviation; MES, mild electrical stimulation; HS, heat shock; IRF-1, interferon regulatory factor-1; LPS, lipopolysaccharide; IP, intraperitoneally; NO, nitric oxide; ANP, acute necrotizing pancreatitis

\section{Introduction}

The chemical group of lazaroid is a C21-amino-steroid complex, devoid of effect on mineralocorticoid and carbohydrate metabolism (glucoactive activity). ${ }^{1}$ Contrary, this complex has a powerful effect against the pathologic lipoperoxidation occurred on lipid membranes. This effect is performed by a steroid-like mechanism lacking the side effects typical of high-dose steroids as methylprednisolone. ${ }^{2}$ All the lazaroid members act as "scavengers" of oxygen free radicals (ROS) such as hydroxyl radical, lipid peroxides and superoxide anion. It inhibits the lipoxygenase and the production and release of arachidonic acid. The U-74389g is the most famous antioxidant agent of that family.

The U-74389g implicates over 254 published biomedical studies at present. The methodology at least of the $46(18.11 \%)$ of these experiments are classified at the tissue ischemia-reperfusion (IR) style. The assumption concerned whether the U-74389g can reverse induced IR injuries in tissues, surrounding organs or even the patients' health. Common affairs were the drug reaction rapidity, the timing of its administration and the dosage height. This antioxidant agent may be proved more beneficial than described. So specific matters are always hardly met in bibliography. A meta-analysis of 34 published related studies yielded a certain numeric efficacy of U-74389g (Table 1). This certain biomedical work tested the effect of U-74389g on a rat liver model. The U-74389g effect was calculated on mean alanine aminotransferase (ALT) levels.

\section{Materials and methods}

\section{Animal preparation}

Legal vet licenses were ascribed under the 3693/November 12 ,
2010 \& 14/January 10, 2012 decisions by the local Prefecture in which the acknowledged Co. Inc SA belongs. All the consumed and non substances, settings and equipment were offered by that $\mathrm{Co}$. at Pikermi - Attiki. The Albino female Wistar rats were managed by the predicted humanistic care. Ad libitum diet accompanied the 7 days pre-experimental normal housing in laboratory. Prenarcosis engaged the nonstop intra-experimental care including general anesthesia, ${ }^{3-6}$ oxygen supply, electrocardiogram and acidometry. Post-experimental euthanasia excluded awakening and preservation of the animals. The rats were successively delivered to four experimental groups; each one containing 10 animals. Thus, the following protocol of IR was performed: The ischemia stage of $45 \mathrm{~min}$ preceded and was common in all groups. However, it was followed by reperfusion for: $60 \mathrm{~min}$ for group A; $120 \mathrm{~min}$ for group B; 60min with immediate U-74389g intravenous (IV) administration for group $\mathrm{C}$ and $120 \mathrm{~min}$ with immediate U-74389g IV administration for group D. The dose of U-74389g was assessed at $10 \mathrm{mg} / \mathrm{Kg}$ body mass of animals. Ischemia was induced by laparotomic clamping inferior aorta over the renal arteries with forceps for $45 \mathrm{~min}$. The clamp removal restored the inferior aorta patency and reperfusion. The U-74389g was administered just at initiation of reperfusion; through inferior vena cava catheter. The ALT levels were assessed at 60th min of reperfusion for A,C groups and at 120th min of reperfusion for B,D groups. The forty female Wistar albino rats were described with mean weight $(\mathrm{mW}): 231.87 \mathrm{~g}$ Standard Deviation (SD): $36.59 \mathrm{~g}$, with minimum $\mathrm{W}: 165 \mathrm{~g}$ and maximum $\mathrm{W}$ : $320 \mathrm{~g}$. Rats' W could be perhaps a confusing factor, e.g. the more obese rats, the higher ALT levels. This assumption was also tested.

The known preceded ischemia of $45 \mathrm{~min}$ for the 20 control rats (mW: $252.5 \mathrm{~g}$ [SD: $39.31 \mathrm{~g}]$ ) was followed by reperfusion.

Group A: Reperfusion lasting 60min (10 controls rats) concerned mW: 243 g [SD: 45.77g] and mean ALT levels 43.6IU/L [Std. Dev: $5.85 \mathrm{IU} / \mathrm{L}]$ (Table 2).

The known preceded ischemia of $45 \mathrm{~min}$ for the 20 control rats (mW: $252.5 \mathrm{~g}$ [SD: $39.31 \mathrm{~g}]$ ) was followed by reperfusion. 
Table I The U-74389g influence ( $\underline{+S D)}$ ) on the levels of some seric variables ${ }^{3}$ concerning reperfusion (rep) time

\begin{tabular}{|c|c|c|c|c|c|c|c|c|}
\hline Variable & Ih Rep & p-Value & I.5h Rep & p-Value & 2h Rep & p-Value & $\begin{array}{l}\text { Interaction of } \\
\text { U-74389g and Rep }\end{array}$ & p-Value \\
\hline WBCC & 0.3544 & 0.0914 & 0.4199 & 0.0045 & 0.5609 & 0.0185 & 0.2973 & 0.0004 \\
\hline $\mathrm{RBCC}$ & 0.021 & $0.7|6|$ & 0.0096 & 0.8106 & -0.0005 & 0.9762 & 0.0158 & 0.4911 \\
\hline Hematocrit & 0.0858 & 0.0852 & 0.0698 & 0.0435 & 0.0733 & 0.2608 & 0.0449 & 0.0196 \\
\hline Hemoglobin & 0.08 & 0.0925 & 0.06 & 0.0604 & 0.059 & 0.3544 & 0.038 & 0.0423 \\
\hline $\mathrm{MCH}$ & 0.0273 & 0.0663 & 0.0297 & 0.0001 & 0.0374 & 0.0003 & $1.33 \%+0.36 \%$ & 0.0005 \\
\hline MCV & 0.0328 & 0.0663 & 0.0357 & 0.0001 & 0.0449 & 0.0003 & 0.0203 & 0.0005 \\
\hline $\mathrm{MCHC}$ & 0.0024 & 0.482 & -0.0032 & 0.1124 & -0.0028 & 0.1603 & -0.0032 & 0.0655 \\
\hline RbcDW & -0.024 & 0.0667 & -0.0269 & 0.0175 & -0.0073 & 0.1383 & -0.0115 & 0.679 \\
\hline Platelet count & -0.0839 & 0.0647 & -0.0704 & 0.0303 & -0.0005 & 0.2939 & -0.0254 & 0.0857 \\
\hline MPV & 0.1436 & 0.0663 & 0.1584 & 0.0001 & 0.2006 & 0.0003 & 0.09 & 0.0005 \\
\hline Platelet-crit & 0.1367 & 0.6373 & 0.1552 & 0.1064 & 0.2369 & 0.0833 & 0.1045 & 0.0712 \\
\hline PDW & 0.0198 & 0.2368 & 0.0255 & 0.0314 & 0.0382 & 0.0807 & 0.0142 & 0.0396 \\
\hline Glucose & -0.0291 & 0.0663 & $-0.065 I$ & 0.0001 & -0.0822 & 0.0003 & -0.0348 & 0.0005 \\
\hline Urea4 & -0.0387 & 0.0663 & -0.0862 & 0.0001 & -0.1087 & 0.0003 & $-0.046 \mid$ & 0.0005 \\
\hline Creatinine & -0.0725 & 0.0663 & -0.1596 & 0.0001 & -0.1997 & 0.0003 & -0.0853 & 0.0005 \\
\hline Uric acid & 0.353 & 0.1614 & 0.2453 & 0.096 & 0.2211 & 0.3946 & 0.1042 & 0.3873 \\
\hline Total protein & -0.0249 & 0.0663 & -0.0558 & 0 & -0.0704 & 0 & -0.0298 & 0 \\
\hline Albumins & -0.0123 & 0.0663 & -0.0276 & 0.0001 & -0.035 & 0.0003 & -0.0148 & 0.0005 \\
\hline AST5 & 0.4904 & 0.0328 & 0.3931 & 0.0593 & 0.3872 & 0.4077 & 0.2481 & 0.0583 \\
\hline$\gamma \mathrm{GT}$ & 0.3793 & 0.2362 & 0.2171 & 0.6442 & 0.1439 & 0.7809 & 0.1023 & 0.8877 \\
\hline ALP & 0.3503 & 0.0663 & 0.396 & 0.0001 & 0.5081 & 0.0003 & 0.2254 & 0.0005 \\
\hline $\mathrm{ACP}$ & -0.9159 & 0.0006 & $-1.136 \mid$ & 0 & -1.2274 & 0 & -0.6482 & 0 \\
\hline CPK & 0.6807 & 0.0012 & 0.5254 & 0.026 & 0.4661 & 0.4951 & 0.2796 & 0.077 \\
\hline CK-MB3 & 0.5716 & 0.0147 & 0.447 & 0.0148 & 0.4534 & 0.2865 & 0.2266 & 0.0745 \\
\hline LDH & 0.2096 & 0.0663 & 0.233 & 0.0001 & 0.2964 & 0.0003 & 0.1325 & 0.0005 \\
\hline Sodium & 0.0188 & 0.0707 & 0.0078 & 0.7714 & 0.0016 & 0.3995 & 0.0004 & 0.3693 \\
\hline Potassium & -0.0532 & 0.0579 & 0.0292 & 0.673 & 0.1262 & 0.3801 & 0.051 & 0.4853 \\
\hline Chloride & 0.0019 & 0.4533 & -0.0044 & 0.0879 & -0.006 & 0.1113 & -0.0037 & 0.0159 \\
\hline Calcium & $0 \%+1.75 \%$ & I & 0.0096 & 0.8782 & 0.0126 & 0.8492 & 0.0078 & 0.8245 \\
\hline Phosphorus & 0.0328 & 0.7966 & 0.0171 & 0.5789 & 0.0348 & 0.8129 & 0.0091 & 0.577 I \\
\hline Magnesium & 0.0492 & 0.7033 & 0.0247 & 0.9171 & 0.0338 & 0.7161 & 0.0494 & 0.8228 \\
\hline Amylase & -0.0285 & 0.0663 & -0.0638 & 0.0001 & -0.0806 & 0.0003 & -0.0341 & 0.0005 \\
\hline Progesterone & -0.2095 & 0.0663 & -0.4405 & 0.0001 & -0.5353 & 0.0003 & -0.2356 & 0.0005 \\
\hline Testosterone6 & 0.6905 & 0.1261 & 0.8086 & 0.0451 & 1.0832 & 0.138 & 0.2915 & 0.5245 \\
\hline Mean & $1.76 \%+27.62 \%$ & 0.2211 & $0.46 \%+29.81 \%$ & 0.1767 & 0.3247 & 0.2394 & 0.1626 & 0.1942 \\
\hline
\end{tabular}

Group A: Reperfusion lasting 60min (10 controls rats) concerned mW: 243 g [SD: 45.77g] and mean ALT levels 43.6IU/L [Std. Dev: $5.85 \mathrm{IU} / \mathrm{L}]$ (Table 2).

Table 2 Weight and ALT levels and Std. Dev. of groups

\begin{tabular}{llll}
\hline Groups & Variable & Mean & Std. Dev \\
\hline A & Weight & $243 \mathrm{~g}$ & $45.77 \mathrm{~g}$ \\
& ALT & $43.6 \mathrm{IU} / \mathrm{L}$ & $5.85 \mathrm{IU} / \mathrm{L}$ \\
B & Weight & $262 \mathrm{~g}$ & $31.10 \mathrm{~g}$ \\
& ALT & $64.5 \mathrm{IU} / \mathrm{L}$ & $39.42 \mathrm{IU} / \mathrm{L}$ \\
$\mathrm{C}$ & Weight & $212.5 \mathrm{~g}$ & $17.83 \mathrm{~g}$ \\
& ALT & $48.8 \mathrm{IU} / \mathrm{L}$ & $6.08 \mathrm{IU} / \mathrm{L}$ \\
$\mathrm{D}$ & Weight & $210 \mathrm{~g}$ & $18.10 \mathrm{~g}$ \\
& ALT & $48.2 \mathrm{IU} / \mathrm{L}$ & $10.55 \mathrm{IU} / \mathrm{L}$
\end{tabular}

\section{Statistical analysis}

The standard t-test was used to determine whether the 4 sets of both weight and ALT levels data are significantly different from each other (Table 3). Any raised significant difference among ALT levels, was investigated whether due to any potent significant weight one. Since the ALT levels could be considered a dependant variable; the drug or no administration, the reperfusion time and their interaction could be considered as multivariate independent variables; the general linear models were used to determine how much the dependant variable is influenced by the independent ones (Table 3 ).
Table 3 Statistical significance of mean values difference for groups (DG) after statistical standard $t$ test application

\begin{tabular}{llll}
\hline DG & Variable & Difference & p-Value \\
\hline A-B & Weight & $-19 \mathrm{~g}$ & 0.2423 \\
& ALT & $-20.9 \mathrm{IU} / \mathrm{L}$ & 0.1022 \\
A-C & Weight & $30.5 \mathrm{~g}$ & 0.0674 \\
& ALT & $-5.2 \mathrm{IU} / \mathrm{L}$ & 0.0699 \\
A-D & Weight & $33 \mathrm{~g}$ & 0.0673 \\
& ALT & $-4.6 \mathrm{IU} / \mathrm{L}$ & 0.3470 \\
B-C & Weight & $49.5 \mathrm{~g}$ & 0.0019 \\
& ALT & $15.7 \mathrm{IU} / \mathrm{L}$ & $0.208 \mathrm{I}$ \\
B-D & Weight & $52 \mathrm{~g}$ & 0.0009 \\
& ALT & $16.3 \mathrm{IU} / \mathrm{L}$ & 0.2185 \\
C-D & Weight & $2.5 \mathrm{~g}$ & 0.739 \\
& ALT & $0.6 \mathrm{IU} / \mathrm{L}$ & 0.8508 \\
\hline
\end{tabular}

\section{Results}

The U-74389g administration non-significantly declined the ALT levels by $5.55 \mathrm{IU} / \mathrm{L}[-19.41 \mathrm{IU}-8.31 \mathrm{IU} / \mathrm{L}](\mathrm{p}=0.4227)$. This finding was accordant with the results of standard t-test $(\mathrm{p}=0.4109)$. Reperfusion time kept non-significantly elevated the ALT levels by $10.15 \mathrm{IU} / \mathrm{L}[-3.42 \mathrm{IU}-23.72 \mathrm{IU} / \mathrm{L}](\mathrm{p}=0.1385)$ also accordant with standard $\mathrm{t}$-test outcome $(\mathrm{p}=0.1233)$. However, the interaction of U-74389g administration and reperfusion time together nonsignificantly declined the ALT levels by $3.13 \mathrm{IU} / \mathrm{L}$ [-11.50IU- 
$5.23 \mathrm{IU} / \mathrm{L}](\mathrm{p}=0.4527)$. Tables $4 \& 5$ sum up the alteration influence of U-74389g versus reperfusion time after the co-evaluation of the above with Table 3. Inserting the rats weight also as an independent variable at generalized linear models analysis, a non-significant relation results in ( $\mathrm{p}=0.1695)$, so as to further investigation was interrupted.

Table 4 The alteration influence of $U-74389 \mathrm{~g}$ in connection with reperfusion time

\begin{tabular}{lllll}
\hline \multicolumn{5}{c}{ p-Values } \\
\hline Alteration & $95 \%$ c. in. & Reperfusion Time & t-test & glm \\
\hline$-5.2 \mathrm{IU} / \mathrm{L}$ & $-0.4 \mathrm{IIU}-10.8 \mathrm{IIU} / \mathrm{L}$ & $\mathrm{Ih}$ & 0.0699 & 0.0673 \\
$5.55 \mathrm{IU} / \mathrm{L}$ & $-19.4 \mathrm{IU}-8.3 \mathrm{IIU} / \mathrm{L}$ & $\mathrm{I} .5 \mathrm{~h}$ & 0.4109 & 0.4227 \\
$16.3 \mathrm{IU} / \mathrm{L}$ & $-43.4 \mathrm{II}-10.8 \mathrm{IIU} / \mathrm{L}$ & $2 \mathrm{~h}$ & 0.2185 & 0.2228 \\
$-10.15 \mathrm{IU} / \mathrm{L}$ & $-3.42 \mathrm{IU}-23.72 \mathrm{IU} / \mathrm{L}$ & Reperfusion time & 0.1233 & 0.1385 \\
$3.136364 \mathrm{IU} / \mathrm{L}$ & $-11.50 \mathrm{IU}-5.23 \mathrm{IU} / \mathrm{L}$ & interaction & & 0.4527 \\
\hline
\end{tabular}

Table 5 The (\%) alteration influence of U-74389g in connection with reperfusion time

\begin{tabular}{llll}
\hline Alteration & +SD & Reperfusion Time & p-values \\
\hline II. $25 \%$ & $6.19 \%$ & Ih & 0.0686 \\
$-8.83 \%$ & $11.25 \%$ & I.5h & 0.4168 \\
$-28.92 \%$ & $24.55 \%$ & $2 \mathrm{~h}$ & 0.2206 \\
$16.14 \%$ & $11.01 \%$ & reperfusion time & 0.1309 \\
$-4.98 \%$ & $6.77 \%$ & interaction & 0.4527 \\
\hline
\end{tabular}

\section{Discussion}

Ischemic situations may influence the ALT levels. Liu SQ et al., found significantly higher by $45.35 \%$ the IR post-operative ALT levels for the detection of liver damage with hand suturing, than sutureless group $(\mathrm{P}<0.01)$ reducing the complications and the extent of injury in adult dogs. Sosnowski P et al., ${ }^{8}$ observed an increase in both ALT activity and liver tissues free radicals level after hind limb IR in rats. Teoh NC et al., ${ }^{9}$ observed ALT levels release exacerbation 24hours after induced steatohepatitis or simple steatosis hepatic IR in foz/foz mice than wild-type littermates. Ikeda A et al., ${ }^{10}$ found serum ALT levels significantly less in rat pre-transplanted liver grafts preserved in the University of Wisconsin (UW) solution containing 5\% CO (CO-UW solution) group for 21 hours, than preserved in the control UW group one in Lewis rats. Oba $\mathrm{M}$ et al., ${ }^{11}$ suppressed the hepatic IR-induced release of serum ALT levels three-fold, after heat shock (HS) (42 degrees C) and/or mild electrical stimulation (MES) (12V) for 20 min than sham ones in mice. Kim KH et al., ${ }^{12}$ counted elevated ALT levels in the short-term period (3hours) in a model of orthotopic rat liver transplantation pretreated 4days before graft harvesting with interferon regulatory factor-1 (IRF-1) than uninfected control liver graft donors. IRF-1 is an important regulator of IR injury after OLT in rats and may be a potential strategy to ameliorate ischemic liver injury after transplantation. Pulitanò $\mathrm{C}$ et al., ${ }^{13}$ found the postoperative serum ALT levels significantly lower in group provided $500 \mathrm{mg}$ of methylprednisolone preoperatively than control one in liver injury patients following liver operation. Fiorini RN et al., ${ }^{14}$ found ALT levels decreased after hepatic IR in all ob/ob mice pretreated with $85 \mathrm{mg} / \mathrm{kg}$ epigallocatechin gallate than control ones.

Also, ALT levels are perhaps influenced by U-74389g. Fukuma K et al., ${ }^{15}$ investigated whether lazaroid U-74389g (nonglucocorticoid analogs of methylprednisolone with multiple actions) could attenuate endotoxin-induced liver injury. They hypothesized that U-74389g treatment may suppress hepatic proinflammatory gene up-regulation through inhibition of activation of nuclear factor $\kappa \mathrm{B}$ (NF- $\mathrm{kB})$. They also compared the efficacy of U-74389g in endotoxin-induced liver injury. Lipopolysaccharide (LPS) (Escherichia coli, 30mg/kg given intraperitoneally (IP) was administered along with U-74389g (3mg/ $\mathrm{kg}$ IP) in male IR mice. U-74389g treatment significantly increased survival rates 48 hours after LPS injection and protected against LPSinduced liver injury in vivo, as indicated by the hepatic enzyme release. These findings suggest that U-74389g can suppress proinflammatory gene up-regulation through inhibition of NF- $\mathrm{KB}$ activation and that it is a promising new antioxidant drug for the treatment of endotoxin shock. Altavilla D et al., ${ }^{16}$ investigated the effect of the 21 -aminosteroid $\mathrm{U}-74389 \mathrm{~g}$ on the 1-arginine-nitric oxide (NO) pathway in a rat model of endotoxin shock. Endotoxin shock was produced by a single IV injection of $20 \mathrm{mg} / \mathrm{kg}$ of Salmonella Enteritidis LPS in male rats. Rats were treated with $\mathrm{U}-74389 \mathrm{~g}(7.5,15$ and $30 \mathrm{mg} / \mathrm{kg}$ IV) or vehicle $(1 \mathrm{ml} / \mathrm{kg} \mathrm{IV}) 5 \mathrm{~min}$ after endotoxin challenge. LPS administration enhanced plasma concentration of ALT. Treatment with U-74389g (15 and $30 \mathrm{mg} / \mathrm{kg}$ IV, $5 \mathrm{~min}$ after endotoxin challenge) significantly ameliorated liver function. Alhan E et al., ${ }^{17}$ investigated the influence of U-74389g on acute necrotizing pancreatitis (ANP) induced by glycodeoxycholic acid in rats. The induction of ANP resulted in a significant increase in serum levels of ALT.

\section{Conclusion}

U-74389g administration whether it interacted or not with reperfusion time non-significantly restored the ALT levels. Specifically, the U-74389g got on suppresses the ALT levels from the significant level to non-significant one. Further biochemical research should elucidate that restore capacity of U-74389g on ALT activity. This capacity may be ascribed to its antioxidant property.

\section{Acknowledgments}

This study was funded by Scholarship by the Experimental Research Centre ELPEN Pharmaceuticals (E.R.C.E), Athens, Greece. The research facilities for this project were provided by the aforementioned institution.

\section{Conflicts of interest}

Author declares there are no conflicts of interest.

\section{Funding}

None.

\section{References}

1. https://www.caymanchem.com/app/template/Product.vm/catalog/75860

2. Fenglin Shi, Jennifer Cavitt, Kenneth L Audus. 21-aminosteroid and 2-(aminomethyl)chromans inhibition of arachidonic acid-induced lipid peroxidation and permeability enhancement in bovine brain microvessel endothelial cell monolayers. Free Radical Biology and Medicine. 1995;19(3):349-357.

3. Tsompos C, Panoulis C, Toutouzas K, et al. The Effect of the Antioxidant Drug "U-74389g" on CK-MB Levels during Ischemia Reperfusion Injury in Rats. Journal of Molecular Biomarkers and Diagnosis. 2015;37(3):91-97.

4. Tsompos C, Panoulis C, Toutouzas K, et al. The effect of the antioxidant drug "U-74389g" on urea during ischemia reperfusion injury in rats. Italian Journal of Medecine. 2015.

5. Tsompos C, Panoulis C, Toutouzas K, et al. The effect of the antioxidant drug U-74389g on AST levels during ischemia reperfusion injury in rats. Journal of Nursing and Health Studies. 2016. p.347-350.

6. Tsompos C, Panoulis C, Toutouzas K, et al. The effect of the antioxidant drug "U-74389g" on testosterone levels during hypoxia reoxygenation injury in rats. Research Journal of Pharmacology and Toxicology. 2016. 
7. Liu SQ, Lei P, Cui XH, et al. Sutureless anastomoses using magnetic rings in canine liver transplantation model. J Surg Res. 2013;185(2):923-933.

8. Sosnowski P, Krauss H, Bogdanski P, et al. The influence of shortterm L-arginine supplementation on rats' muscular and hepatic cells in ischemia-reperfusion syndrome. J Physiol Biochem. 2012;68(1):1-9.

9. Teoh NC, Williams J, Hartley J, et al. Short-term therapy with peroxisome proliferation-activator receptor-alpha agonist Wy-14,643 protects murine fatty liver against ischemia-reperfusion injury. Hepatology. 2010;51(3):996-1006

10. Ikeda A, Ueki S, Nakao A, et al. Liver graft exposure to carbon monoxide during cold storage protects sinusoidal endothelial cells and ameliorates reperfusion injury in rats. Liver Transpl. 2009;15(11):1458-1468.

11. Oba M, Suico MA, Morino S, et al. Modified mild heat shock modality attenuates hepatic ischemia/reperfusion injury. J Surg Res. 2010;162(2):213-220.

12. Kim KH, Dhupar R, Ueki S, et al. Donor graft interferon regulatory factor-1 gene transfer worsens liver transplant ischemia/reperfusion injury. Surgery. 2009;146(2):181-189.
13. Pulitanò C, Aldrighetti L, Arru M, et al. Prospective randomized study of the benefits of preoperative corticosteroid administration on hepatic ischemia-reperfusion injury and cytokine response in patients undergoing hepatic resection. HPB (Oxford). 2007;9(3):183-189.

14. Fiorini RN, Donovan JL, Rodwell D, et al. Short-term administration of (-)-epigallocatechin gallate reduces hepatic steatosis and protects against warm hepatic ischemia/reperfusion injury in steatotic mice. Liver Transpl. 2005;11(3):298-308.

15. Fukuma K, Marubayashi S, Okada K, et al. Effect of lazaroid U-74389g and methylprednisolone on endotoxin-induced shock in mice. Surgery. 1999;125(4):421-430.

16. Altavilla D, Squadrito F, Campo GM, et al. The lazaroid, U-74389g, inhibits inducible nitric oxide synthase activity, reverses vascular failure and protects against endotoxin shock. Eur J Pharmacol. 1999;369(1):49-55.

17. Alhan E, Türkyilmaz S, Erçin C, et al. Effects of lazaroid U-74389g on acute necrotizing pancreatitis in rats. Eur Surg Res. 38(2):70-75. 